\title{
A versatile heterogeneous photocatalyst: nanoporous gold powder modified with a zinc(II) phthalocyanine derivative for singlet oxygen [4+2] cycloadditions
}

\author{
David Steinebrunner ${ }^{1,2} \odot$. Günter Schnurpfeil ${ }^{3} \cdot$ Hans Hannes Doebler ${ }^{1} \cdot$ Jorge Adrian Tapia Burgos ${ }^{1,2} \odot$. \\ Dieter Wöhrle ${ }^{3} \cdot$ Arne Wittstock $^{1,2}$ (1)
}

Received: 3 February 2021 / Accepted: 22 March 2021 / Published online: 19 April 2021

(c) The Author(s) 2021

\begin{abstract}
Nanoporous gold was functionalized with a photosensitizer, a zinc(II) phthalocyanine derivative. Such systems are active for the generation of reactive singlet oxygen which can be used for photocatalytic oxidation reactions. This study aims to demonstrate the versatility of such an approach, in terms of substrates and the employed solvent, only possible for a truly heterogeneous catalytic system. The activity of the hybrid system was studied for [4+2] cycloadditions of three different types of dienes and a total of eight substrates in two organic solvents and once in water. The highest activity was measured for 1,3-diphenylisobenzofuran, which is also highest in terms of sensitivity for the reaction with ${ }^{1} \mathrm{O}_{2}$. Trends in conversion could be anticipated based on reported values for the rate constant for the reaction of ${ }^{1} \mathrm{O}_{2}$. In almost all cases, an amplification of the conversion by immobilization of the sensitizer onto nanoporous gold was observed. The limiting case was ergosterol, which was the largest of all substrates with a van-der-Waals radius of about $2.1 \mathrm{~nm}$. Additional factors such as the limited lifetime of ${ }^{1} \mathrm{O}_{2}$ in different solvents as well as the hampered diffusion of the substrates were identified.
\end{abstract}

Graphic abstract

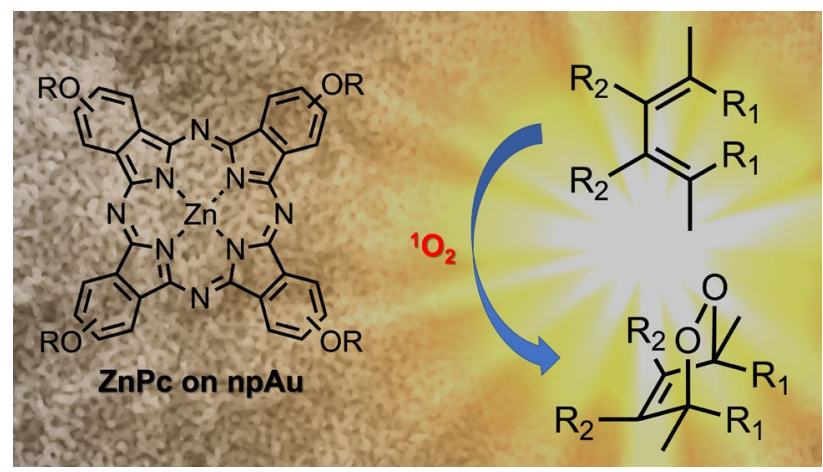

Keywords Photooxidation $\cdot$ Nanoporous gold $\cdot$ Phthalocyanine $\cdot$ Singlet oxygen $\cdot$ Heterogeneous photocatalyst

\section{Introduction}

Dieter Wöhrle

woehrle@uni-bremen.de

$\triangle$ Arne Wittstock awittstock@uni-bremen.de

Extended author information available on the last page of the article
The generation of oxygenated compounds by reactive singlet oxygen $\left({ }^{1} \mathrm{O}_{2}\right)$ is an important step in organic synthesis [1, 2]. About 30 years ago, its use for the synthesis of natural products has emerged and was since then developed further [3]. ${ }^{1} \mathrm{O}_{2}$ can be generated chemically [4] or by direct excitation with light [5]. Due to the spin forbidden nature 
of this process the most common and practical way of ${ }^{1} \mathrm{O}_{2}$ generation is by photosensitization [6]. Indeed, this method is quite common in nature [7]. Here, the photosensitizer is first excited by light and undergoes intersystem crossing (ISC), followed by transfer of the energy to molecular (triplet) oxygen resulting in the formation of singlet oxygen (see also Eqs. 1-3). This singlet oxygen can be used in the synthesis of oxygenated compounds by reaction of carbon or heteroatomic double bonds resulting in endoperoxides $([4+2]$ cycloadditions $)$, dioxetanes $([2+2]$ cycloaddition $)$, hydroperoxides (Schenck ene reaction), and many more [3, 8].

This synthetic route is quite attractive as it only requires molecular oxygen, (visible) light, and a suitable photosensitizer such as phthalocyanine derivatives $(\mathrm{ZnPc})$ [9-11]. This process consists of the following photophysical steps in solution:

$\mathrm{ZnPc} \stackrel{\mathrm{h}_{v}}{\longrightarrow}{ }^{1} \mathrm{ZnPc}^{*} \stackrel{\mathrm{ISC}}{\longrightarrow}{ }^{3} \mathrm{ZnPc}^{*}$,

${ }^{3} \mathrm{ZnPc}^{*}+{ }^{3} \mathrm{O}_{2} \rightarrow \mathrm{ZnPc}+{ }^{1} \mathrm{O}_{2}$,

${ }^{1} \mathrm{O}_{2}+\mathrm{Sub} \rightarrow$ oxidized Sub.

First (Eq. 1), after excitation of $\mathrm{ZnPc}$ and formation of the excited singlet state ( $\left.{ }^{1} \mathrm{ZnPc} *\right)$ intersystem crossing (ISC) occurs resulting in the excited triplet state $\left({ }^{3} \mathrm{ZnPc} *\right)$. Second (Eq. 2), the spin allowed triplet - singlet energy transfer from ${ }^{3} \mathrm{ZnPc}^{*}$ to triplet oxygen under formation of singlet oxygen occurs. In the last step (Eq. 3), singlet oxygen is reacting with the substrate. Singlet oxygen is a short lived and metastable compound but can diffuse and be used as a reactive compound. The photosensitizer ( $\mathrm{ZnPc} 1)$ is absorbing in the visible region of light at $\lambda \sim 680 \mathrm{~nm}$ with high extinction coefficients of $\varepsilon_{680} \sim 140.000 \mathrm{~L} \mathrm{~mol}^{-1} \mathrm{~cm}^{-1}$ (Fig. 1a).

Typically, the photosensitizer is dissolved in the reaction medium to enable diffusion and reaction of the singlet oxygen and the substrate. For practical application, it is, however, useful to prepare heterogeneous catalysts by chemical attachment of the sensitizer to suitable supports such as inorganic silanes [12, 13]. In this way, the heterogeneous catalyst can be physically separated from the reaction medium and more easily applied into various reactor concepts.

An important requirement for such supports is a high surface to volume ratio, exposing a large fraction of the functionalized surface, and, thus, sensitizer to the light. Simply, by structuring the support on the nanoscale, an amplification of the surface area is achieved by several orders of magnitude. Also, such nano-engineered materials show a number of exclusive physicochemical properties non-existent for materials either on larger (micro- and macroscopic) or smaller (molecular) scales. One interesting example of such a material is nanoporous gold (npAu) [14, 15]. This material is prepared by selectively etching $\mathrm{Ag}$ from $\mathrm{Ag} /$ $\mathrm{Au}$ alloys using concentrated nitric acid. A uniform nanoporous structure with identical interconnected nanometersized pores and gold ligaments across the entire volume is obtained (Fig. 1b). Dependent on the reaction conditions of the etching process, the pore sizes can range from around 7-70 $\mathrm{nm}$ in average diameter [16]. This support provides a high specific surface area of about $10 \mathrm{~m}^{2} / \mathrm{g}$ and exposes a large surface per volume to the irradiating light. Yet, it was also found to enhance the fluorescent signals of nearby phthalocyanines on the surface known as metal-enhanced fluorescence $[17,18]$. This effect originates from the excitation of localized surface plasmon resonance (LSPR) of collective conduction-band electrons of the metallic support that can modify the quantum yield of adjacent fluorophores [19]. Two characteristic plasmon bands of npAu have been detected in optical transmission spectra (Fig. 1c). One at $\lambda \sim 490 \mathrm{~nm}$ resulting from the resonant absorption of gold films is independent of nanopore sizes and dielectric surroundings. The other at $\lambda \sim 550-650 \mathrm{~nm}$ arises from the excitation of localized surface plasmon resonance and shows a band shift with the nanopore sizes [20].
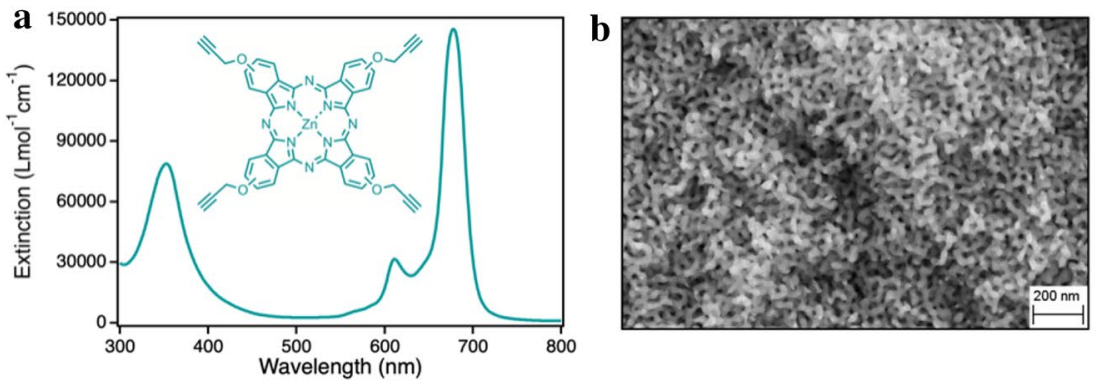

Fig. 1 Structure and corresponding optical spectrum for a the photosensitizer zinc(II) phthalocyanine 1 with peripheral propynoxysubstituents. b SEM image of nanoporous gold with pore sizes of

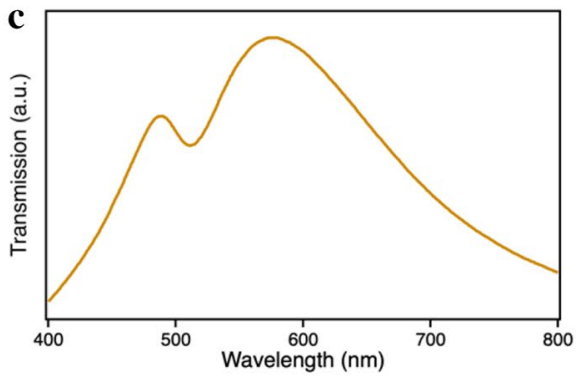

20-25 nm, and c corresponding transmission spectrum of a npAu foil with comparable pore sizes. All spectra were recorded employing $\mathrm{DMF}$ as solvent $(\mathrm{ZnPc})$ or as dielectric environment (npAu) 
Recently, we reported a hybrid system where a $\mathrm{ZnPc}$ derivative was immobilized on different shaped nanoporous gold supports as heterogeneous, monolithic systems, and coatings [16, 21, 22]. With these hybrid materials under irradiation with visible light a very efficient singlet oxygen formation compared to the same amount of $\mathrm{ZnPc}$ in solution was shown using 1,3-diphenylisobenzofuran (DPBF) as active singlet oxygen quencher. This effect is caused by the interaction of npAu and the immobilized $\mathrm{ZnPc}[21,22]$.

However, central questions remain. As this system is heterogeneous, the reagents, i.e., the singlet oxygen as well as the substrate have to diffuse to one another to react. Does the reaction proceed mainly in the pores of the $\mathrm{npAu}$ ? Also, the singled oxygen is metastable and has a limited lifetime on the order of only a few $\mu$ s. While the system is truly heterogeneous and not limited by the solubility of the sensitizer, the lifetime of singlet oxygen is strongly dependent on the solvent [5, 23-26]. Which solvent provides a long enough lifetime to enable diffusion of the reactive oxygen? Last but not least, the strong suit of the ${ }^{1} \mathrm{O}_{2}$ oxidation of organic compounds is its versatility and applicability to a wide range of substrates bearing double bonds. Does the reaction in the hybrid system with singlet oxygen proceeds the same way as in solution?

Based on these questions we investigated the system of $\mathrm{ZnPc}$ immobilized on powdered npAu support for the oxidation of a variety of substrates, namely furan derivatives, anthracene derivatives, and 1,3-cyclohexadiene based structures, the largest substrate is ergosterol with a van-der-Waals diameter of about $2.1 \mathrm{~nm}$. These substrates are commercially available to a reasonable price. By a [4+2] cycloaddition with singlet oxygen all of these substrates should be converted into their oxygenated counterparts. If the reaction proceeds as reported in the liquid phase, differences in reactivity should be attributed to the rate constant of the reaction between ${ }^{1} \mathrm{O}_{2}$ and the substrate (Eq. 3). We will also vary the solvents from $N, N$-dimethylformamide (DMF) to acetonitrile $(\mathrm{ACN})$ as well as water, enabling a singlet oxygen lifetime from $60 \mu$ s down to below $1 \mu$ s for water [5, 23-26]. Last but not least, the reusability of the catalyst will be tested. Overall, we seek to investigate the versatility of this heterogeneous $\mathrm{ZnPc}-\mathrm{npAu}$ hybrid photocatalyst.

\section{Results and discussion}

\subsection{Synthesis and characterization}

Nanoporous gold powders (npAu) were prepared by leaching of $\mathrm{Ag}$ from a $\mathrm{Au}(30 \mathrm{at} \%) \mathrm{Ag}(70 \mathrm{at} \%)$ master alloy in concentrated nitric acid. This procedure also dubbed free corrosion is known to result in npAu with pore sizes as small as $20 \mathrm{~nm}$, depending on the temperature[27] and dealloying time (Fig. 1b) [16]. The monolithic shape of the starting alloy is retained while the corrosion proceeds and the $\mathrm{Ag}$ fraction is replaced by an open pore volume. In this way, npAu shaped in the form of disks with a macroscopic diameter of about $5 \mathrm{~mm}$ and a thickness of about $200 \mu \mathrm{m}$ were prepared. Fracturing by physical means was achieved using tweezers. The resulting powder was comprised of about $25 \mu \mathrm{m}$ large $\mathrm{npAu}$ particles (Figure S1).

Functionalization of the npAu powder with the $\mathrm{ZnPc}$ derivative to obtain the npAu-ZnPc hybrid system was carried out in two-steps as developed by us (Scheme 1) [22]. Compared to a direct immobilization of thiol-substituted $\mathrm{ZnPcs}$, the two-step approach offers several benefits. The synthetic effort can be significantly reduced while on the same time the long-time stability of the building blocks is higher than for thiol-substituted ZnPcs. In addition, the obtained SAMs prepared from alkanethiols usually exhibit a higher order compared to SAMs prepared from large macrocycles [28]. The surface of the npAu powder
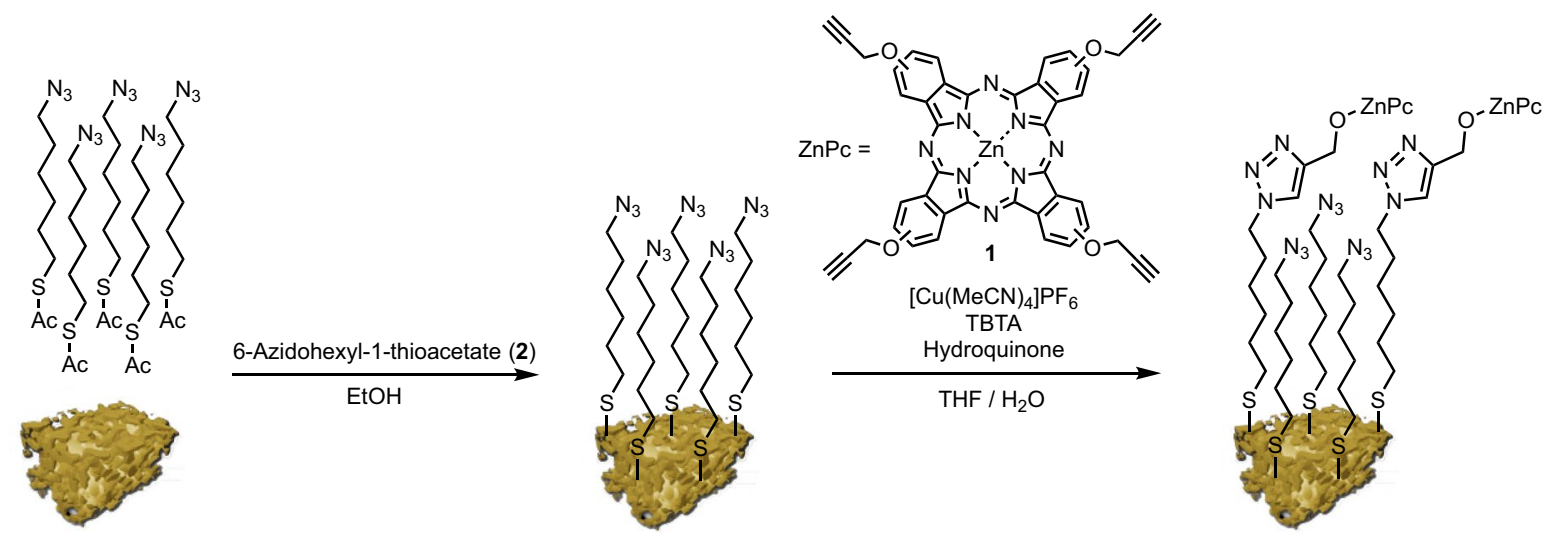

Scheme 1 Schematic representation for the two-step functionalization of the npAu powder; formation of a self-assembled monolayer (SAM) on npAu with 6-azidohexyl-1-thioacetate $\mathbf{2}$ followed by copper catalyzed azide-alkyne cycloaddition ("click reaction") with the ZnPc derivative $\mathbf{1}$ 
was functionalized by a SAM of 6-azidohexyl-1-thioacetate $\mathbf{2}$. Then the $\mathrm{ZnPc}$ derivative $\mathbf{1}$ was bound to the free azide groups of the SAM via copper catalyzed azide-alkyne cycloaddition (CuAAC). The successful formation of the triazole ring was studied by $\mathrm{X}$-ray photoelectron spectroscopy (XPS) and is in good agreement with previous studies reported in the literature (Figure S2) [29]. After functionalization, the particle size and the porous structure of npAu remained unchanged. The employed alkyl chain length of the azidothioacetate and the peripheral side chains of the $\mathrm{ZnPc}$ derivative were selected because the obtained hybrid material with a distance of $\sim 1.3 \mathrm{~nm}$ between $\mathrm{npAu}$ and $\mathrm{ZnPc}$ under irradiation exhibits a preferable coupling between the plasmonic states of npAu and the $\mathrm{ZnPc}$ to achieve the highest singlet oxygen generation [21]. The energy dispersive X-ray spectroscopy (EDX) measurements of all samples showed a homogeneous zinc distribution, which was confirmed by EDX mapping and line scan experiments as described before by us [22]. By inductively-coupled plasma mass spectrometry (ICP-MS) the amount of immobilized $\mathrm{Zn}$ was determined as $\sim 350 \mu \mathrm{g}$ per $\mathrm{g}$ hybrid catalyst.

The photooxidation reactions were conducted under oxygen by irradiation with visible light of $180 \mathrm{mWcm}^{-2}$ (Figure S3). A $550 \mathrm{~nm}$ cut-on filter was used for simultaneous irradiation of the plasmon resonance of npAu between 550 and $650 \mathrm{~nm}$ and the Q-band of the immobilized $\mathrm{ZnPc}$ at $690 \mathrm{~nm}$ (Fig. 1), and to avoid irradiation at shorter wavelengths. After transmission spectra of npAu films the penetration depth of visible light in this material is only around $300 \mathrm{~nm}$ $[16,22]$. This means that in the npAu-ZnPc powder system up to this depth, npAu and $\mathrm{ZnPc}$ can contribute by irradiation via their excited states to the generation of singlet oxygen for the photooxidation reactions. Therefore, considering the $\mathrm{ZnPc}$ loading of $350 \mu \mathrm{mol} / \mathrm{g}$ and the employed hybrid catalyst quantity of $28 \mathrm{mg}$, the active and irradiated parts correspond to around $0.5 \mathrm{nmol} \mathrm{ZnPc}$. A great excess of substrates of 10 or $5 \mu \mathrm{mol}$ was employed which corresponds to a molar ratio of substrate:active $\mathrm{ZnPc}=20.000: 1$ or 10.000:1, respectively. The consumption of the substrates over time was measured via UV-Vis spectroscopy and the turnover numbers (TON) and the turnover frequencies (TOF) were determined. It was found that after the TON graphs in every case the photooxidations obey a zero-order kinetic during the first minutes. Larger deviations were observed for prolonged use of the photocatalyst which might be due to photobleaching of the ZnPc 1 by singlet oxygen caused degradation. It is important to note that the unfunctionalized npAu powder or modified only by the azidothioate $\mathbf{2}$ under irradiation shows no generation of ${ }^{1} \mathrm{O}_{2}$.

\subsection{Reaction of ${ }^{1} \mathrm{O}_{2}$ with furan derivatives}

The photooxidation of three furan derivatives was investigated. Furans are 1,3-heterodienes, in the presence of singlet oxygen they undergo $[4+2]$-cycloadditions at the double bond in 2,5-positions under formation of the unstable endoperoxides $\mathbf{3 b} \mathbf{- 5} \mathbf{b}$ which undergo further reactions to the final products (Scheme 2) [4, 37-39]. We selected 1,3-diphenylisobenzofuran (DPBF) 3a because this compound exhibits a very high reactivity and sensitivity [6] against singlet oxygen $[26,40]$. The reaction in DMF started immediately after irradiation, indicated by the decrease of the DPBF absorption at $\lambda=415 \mathrm{~nm}$ by UV-Vis spectroscopy (Figure S4). Already after $10 \mathrm{~min}$, full conversion of DPBF was observed (Fig. 2; Table 1). The same amount of $\mathrm{ZnPc}$ dissolved in solution resulted only to about $20 \%$ conversion<smiles>c1ccc(-c2oc(-c3ccccc3)c3ccccc23)cc1</smiles>

3a

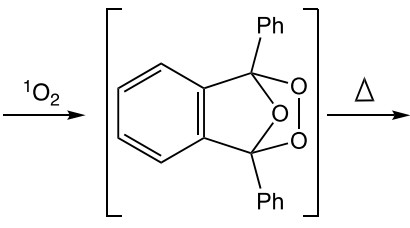

$3 \mathbf{b}$<smiles>O=C(c1ccccc1)c1ccccc1C(=O)c1ccccc1</smiles>

3c

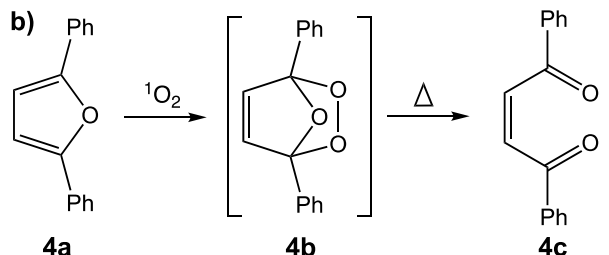

4c

c)<smiles>OCc1ccco1</smiles>

$5 a$

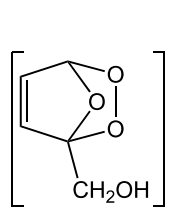

$5 b$

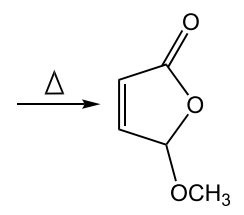

$5 c$

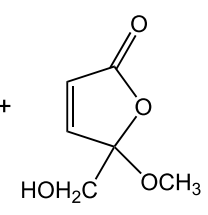

5d
Scheme 2 a [4+2] Cycloaddition of ${ }^{1} \mathrm{O}_{2}$ to DPBF 3a. The at first obtained unstable endoperoxide $\mathbf{3 b}$ reacts further to 1,2-dibenzoylbenzene $\mathbf{3 c}$ as final stable product. b The $[4+2]$ cycloaddition of 2,5-diphenylfuran (DPF) $4 \mathbf{a}$ with ${ }^{1} \mathrm{O}_{2}$ leads via the unstable endop- eroxide $\mathbf{4 b}$ to cis-1,2-dibenzoylethene $4 \mathbf{c}$. $\mathbf{c}$ The reaction of furfuryl alcohol 5a with ${ }^{1} \mathrm{O}_{2}$ results via the thermally unstable endoperoxide $\mathbf{5 b}$ in 5-methoxy-2(5H)-furanone $\mathbf{5 c}$ and 5-methoxy-5-hydroxymethyl-2-furanone $\mathbf{5 d}$, as major reaction products 

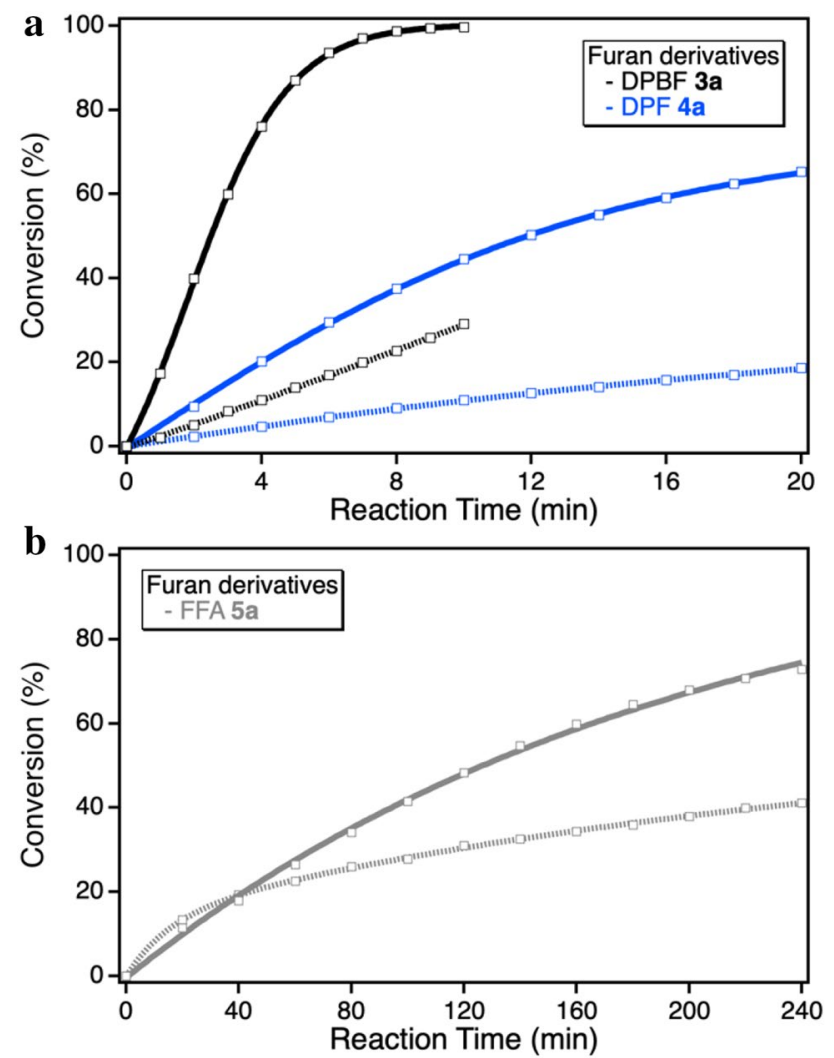

Fig. 2 a Photocatalytic conversion of DPBF 3a (black) and DPF 4a (blue) over time in DMF and $\mathbf{b}$ of FFA $\mathbf{5 a}$ (gray) in ACN by oxidation with ${ }^{1} \mathrm{O}_{2}$ employing the $\mathrm{ZnPc}$ photocatalyst immobilized on $\mathrm{npAu}$ (bold line) and for comparison the same amount of $\mathrm{ZnPc}$ in solution (dashed line)

after the same reaction time. The synergistic effect between the npAu and $\mathrm{ZnPc}$ results, hence, in an increase of conversion by a factor of more than 5 [22].

The linear run of the conversion and TON, respectively, showed that the photooxidation follows zero-order kinetics until saturation effects become dominant. From the slope of the linear regime, a high turnover frequency of $1949 \mathrm{~min}^{-1}$ was calculated. This was the highest activity measured for all substrates in this study and is reflected by the comparably high reaction constant $\left(5 \cdot 10^{8} \mathrm{Lmol}^{-1} \mathrm{~s}^{-1}\right)$ for the reaction of singlet oxygen with this substrate. Also 2,5-diphenylfuran (DPF) 4a was investigated as chemical trap for detection of singlet oxygen (Scheme 2b) $[4,41]$. The rate constant for the reaction of singlet oxygen with DPF is about $0.7 \cdot 10^{8}$ $\mathrm{Lmol}^{-1} \mathrm{~s}^{-1}$ (Table 1). As expected, the conversion after $20 \mathrm{~min}$ is lower with $65 \%$ conversion and a corresponding TOF of $281.9 \mathrm{~min}^{-1}$ due to the lower rate constant (Figs. 2 and S5). Next, the oxidation of a further furan derivative, furfuryl alcohol (FFA) 5a was studied (Scheme 2c). Again, the conversion set in right after irradiation and the decay of the signal at $\lambda=221$ was detected (Figure S6). Even though a rate constant of the reaction in water was reported of about $1 \cdot 10^{8} \mathrm{Lmol}^{-1} \mathrm{~s}^{-1}$, the measured conversion in acetonitrile accounts to only $70 \%$ after $240 \mathrm{~min}$ and is, hence, much lower as for DPBF. As in the case of $\mathbf{3 a}$, the activities for the photooxidation of $\mathbf{4 a}$ and $\mathbf{5 a}$ with the $\mathrm{ZnPc}$ in solution are lower compared to the heterogeneous hybrid photocatalyst (Fig. 2).

\subsection{Reaction of ${ }^{1} \mathrm{O}_{2}$ with anthracene derivatives}

A further class of conjugated diene analogues are anthracene derivatives which bear at the 9,10-positions two double bonds with a high reactivity in chemical reactions (Scheme 3). Two anthracene derivatives which are also commercially available were now investigated for the reaction with ${ }^{1} \mathrm{O}_{2} \cdot 9,10$-dimethylanthracene (DMA) 6a as well as 9,10-anthracenediyl-bis(methylene)dimalonic acid (ABDA) 7a which were also described as chemical traps for singlet oxygen [6, 33, 42-45]. DMA reacts selectively with singlet oxygen after a $[4+2]$-cycloaddition to form the 9,10-endoperoxide $\mathbf{6 b}$ (Scheme 3). Right after starting the irradiation a decrease of the absorption at $\lambda=379 \mathrm{~nm}$ was observed by UV-Vis spectroscopy indicating the reaction with ${ }^{1} \mathrm{O}_{2}$ (Figure S7). After 60 min about $80 \%$ of DMA was converted to the corresponding endoperoxide. The same amount of $\mathrm{ZnPc} 1$ in solution showed only a conversion of $25 \%$ during
Table 1 Summary of conversion of the various substrates by ${ }^{1} \mathrm{O}_{2}$ in the respective solvent (DMF: $N, N$-dimethylformamide, $\mathrm{ACN}$ : acetonitrile)

\begin{tabular}{|c|c|c|c|}
\hline Substrate & Solvent & $\mathrm{k}_{\mathrm{r}}\left[10^{8} \mathrm{~L} \mathrm{~mol}^{-1} \mathrm{~s}^{-1}\right]$ & Conversion \\
\hline DPBF 3a & DMF & $5\left(\right.$ in $\left.\mathrm{CH}_{3} \mathrm{OH}\right)$ [30] & $100 \%$ after $10 \mathrm{~min}$ \\
\hline DPF 4a & DMF & $0.7\left(\right.$ in $\left.\mathrm{CH}_{2} \mathrm{Cl}_{2}\right)[31]$ & $65 \%$ after $20 \mathrm{~min}$ \\
\hline FFA 5a & $\mathrm{ACN}$ & $1\left(\right.$ in $\left.\mathrm{H}_{2} \mathrm{O}\right)$ [32] & $70 \%$ after $240 \mathrm{~min}$ \\
\hline DMA $6 \mathbf{a}$ & DMF & 1.33 (in $\mathrm{ACN}$ ) [33] & $80 \%$ after $60 \mathrm{~min}$ \\
\hline ABDA 7a & $\mathrm{DMF} / \mathrm{H}_{2} \mathrm{O}$ & $0.1\left(\right.$ in $\left.\mathrm{H}_{2} \mathrm{O}\right)$ [34] & $18 \% / 1 \%$ after $60 \mathrm{~min}$ \\
\hline$\alpha$-Terpinene 8a & $\mathrm{ACN}$ & 1 (in $\mathrm{CHCl}_{3}$ ) [35] & $85 \%$ after $120 \mathrm{~min}$ \\
\hline ERGO 9a & $\mathrm{ACN}$ & 0.3/0.1 $\left(\mathrm{CHCl}_{3} /\right.$ Pyridine $)[35] /[36]$ & $75 \%$ after $240 \mathrm{~min}$ \\
\hline 1,3-CHD 10a & $\mathrm{ACN}$ & $0.07\left(\right.$ in $\left.\mathrm{CHCl}_{3}\right)$ [35] & $40 \%$ after $360 \mathrm{~min}$ \\
\hline
\end{tabular}

The rate constants for the reaction of the particular substrate with ${ }^{1} \mathrm{O}_{2}$ are given according to literature results (solvent). The error bar is typically stated with $\pm 10 \%$ 
a)<smiles>Cc1c2ccccc2c(C)c2ccccc12</smiles>

6a

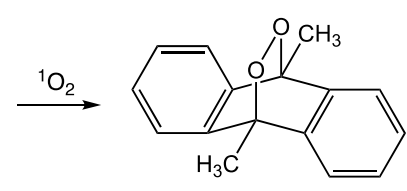

$6 b$
Scheme 3 a $[4+2]$ cycloaddition of ${ }^{1} \mathrm{O}_{2}$ to DMA $\mathbf{6 a}$, resulting in the formation of the endoperoxide $\mathbf{6} \mathbf{b}$ as final stable product [33]. b The reaction of the anthracene derivative 9,10-anthracenediyl-

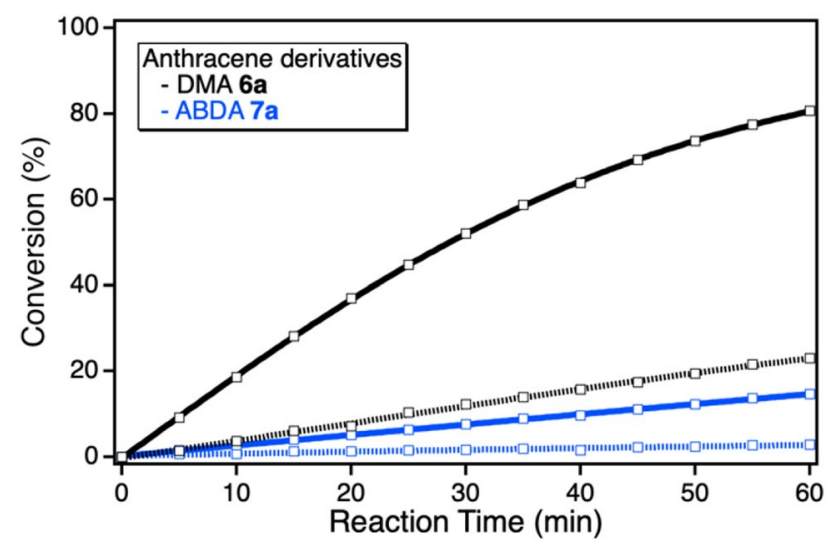

Fig. 3 Photocatalytic conversion of DMA 6a (black) and ABDA 7a (blue) over time in DMF by oxidation with ${ }^{1} \mathrm{O}_{2}$ employing the $\mathrm{ZnPc}$ photocatalyst immobilized on npAu (bold line) and for comparison the same amount of $\mathrm{ZnPc}$ in solution (dashed line)

this time frame. As for the furan derivatives, this reflects an increase of conversion by a factor of 4 due to the synergistic effect of the sensitizer and the npAu support (Fig. 3).

The conversion of the other anthracene derivative 9,10-anthracenediyl-bis(methylene)dimalonic acid (ABDA) 7a by reaction with singlet oxygen was studied in DMF as well as in aqueous solution (Scheme 3b). Using water as a solvent is preferable in the context of green chemistry. However, the problem is the low solubility of most substrates and the limited lifetime of singlet oxygen in this medium as also discussed below. Since ABDA is appreciably soluble in water it is, however, important to be studied as a benchmark. Right after irradiation a decrease of absorption at $\lambda=379 \mathrm{~nm}$ was detected indicating the reaction of ABDA with ${ }^{1} \mathrm{O}_{2}$ (Figure S8). As expected, based on the lower reaction constant by about an order of magnitude in comparison to DMA, the conversion of

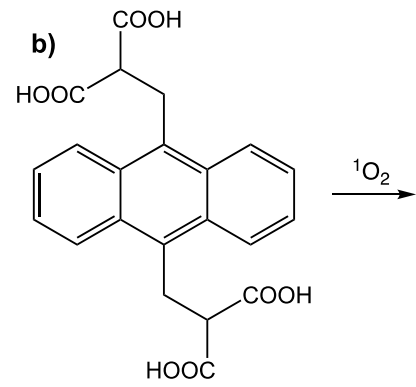

$7 \mathbf{a}$

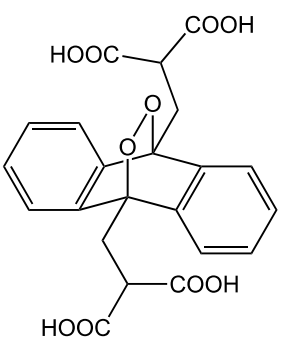

$7 \mathbf{b}$ bis(methylene)dimalonic acid 7a (ABDA) towards ${ }^{1} \mathrm{O}_{2}$ under formation of the endoperoxide $\mathbf{7 b}$

ABDA was determined to $18 \%$ in DMF and even lower at only $1 \%$ in water after 60 min of irradiation (Fig. 3). Assuming a zero-order kinetic and a linear increase of the TON during the first $20 \mathrm{~min}$, TOF values of $53.2 \mathrm{~min}^{-1}$ in DMF and $9.01 \mathrm{~min}^{-1}$ in water were determined.

\subsection{Reaction of ${ }^{1} \mathrm{O}_{2}$ with 1,3 -cyclohexadienes}

A further interesting class of 1,3-dienes which react with ${ }^{1} \mathrm{O}_{2}$ by [4+2] cycloadditions are 1,3-cyclohexadienes such as 1,3-cyclohexadiene[35], $\alpha$-terpinene, and ergosterol. For example, $\alpha$-terpinene 8a reacts with ${ }^{1} \mathrm{O}_{2}$ forming ascaridole 8b (Scheme 4a). This was at first studied in the pioneering work of Schenck using chlorophyll as sensitizer [46-48]. Again, right after irradiation a decay of the UV-Vis signal at $\lambda=267 \mathrm{~nm}$ was observed, indicating the reaction of $\alpha$-terpinene with sensitized ${ }^{1} \mathrm{O}_{2}$ (Figure S9). After $120 \mathrm{~min}$ a conversion of about $85 \%$ was reached, corresponding to a TOF of about $185.3 \mathrm{~min}^{-1}$ (Fig. 4). The same amount of photosensitizer in solution showed a conversion of about $45 \%$. Even though this is still an increase by a factor of 2 due to the synergistic effect of the npAu, it is considerably lower as overserved for the furan and anthracene derivatives.

The sterol ergosterol (ERGO, (22E)-Ergosta-5,7,22trien-3 $\beta$-ol) 9a is a biological precursor of vitamin $\mathrm{D}_{2}$. This compound contains a 1,3-conjugated double bond within the sterol backbone and a single double bond at the side chain (Scheme $4 \mathrm{~b}$ ). Due to the higher reactivity of the conjugated double bond in the reaction with ${ }^{1} \mathrm{O}_{2}$, the endoperoxide $\mathbf{9 b}$ was isolated as main reaction product [49-51]. Right after starting the illumination a decrease of the absorption at $\lambda=282 \mathrm{~nm}$ indicates the reaction with ${ }^{1} \mathrm{O}_{2}$ (Figure S10). A reaction constant for the reaction of ERGO with ${ }^{1} \mathrm{O}_{2}$ of about $0.2 \cdot 10^{8} \mathrm{Lmol}^{-1} \mathrm{~s}^{-1}$ is about one order of magnitude lower as the one for the reaction with $\alpha$-terpinene $[35,49]$. This is reflected by a lower conversion of only $80 \%$ after $240 \mathrm{~min}$ (Fig. 4). Most interestingly, for ergosterol no increase of conversion was detected when the photosensitizer was bound 
a)<smiles>CC1=CC=C(C(C)C)CC1</smiles><smiles>CC(C)C12C=CC(C)(CC1)OO2</smiles>

$8 \mathbf{b}$

c)

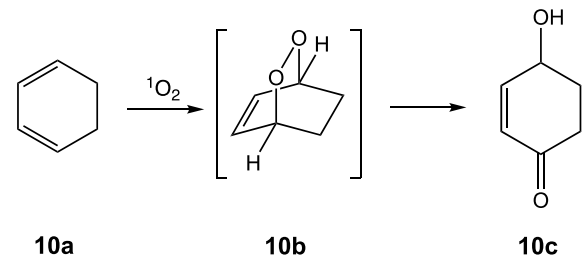

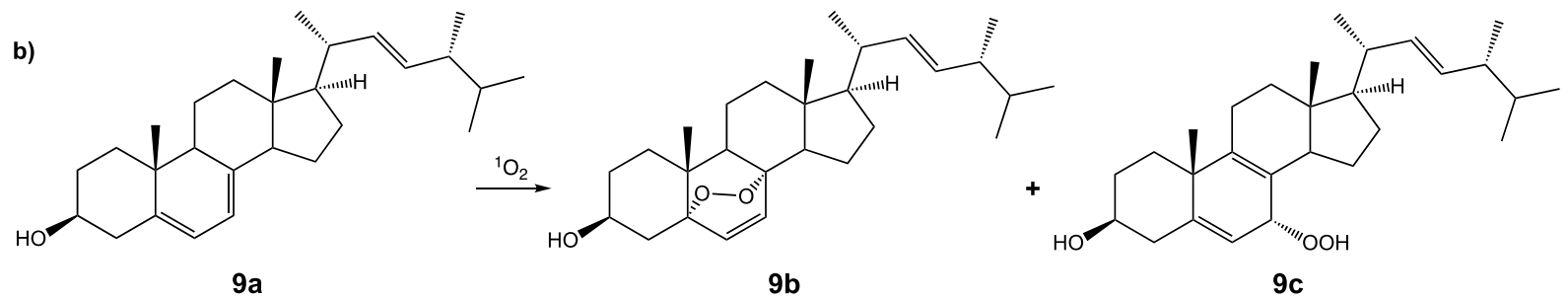

Scheme 4 a $[4+2]$ cycloaddition of ${ }^{1} \mathrm{O}_{2}$ to $\alpha$-terpinene 8a, resulting in the formation of the endoperoxide ascaridole $\mathbf{8 b}$ as final stable product. b Reaction scheme for the addition of ${ }^{1} \mathrm{O}_{2}$ to ergosterol 9a under formation of the endoperoxide $\mathbf{9 b}$ as main product and the

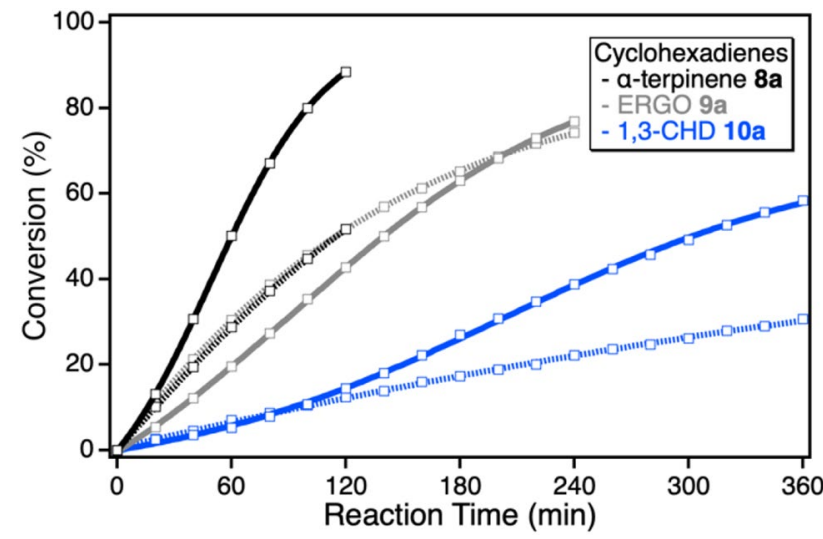

Fig. 4 Photocatalytic conversion of $\alpha$-terpinene 8a (black), ergosterol 9a (blue), and 1,3-cyclohexadiene 10a (gray) over time in ACN by oxidation with ${ }^{1} \mathrm{O}_{2}$ employing the $\mathrm{ZnPc}$ photocatalyst immobilized on npAu (bold line) and for comparison the same amount of $\mathrm{ZnPc}$ in solution (dashed line)

to npAu. This fact can be explained by the large van-derWaals diameter of ERGO of $2.1 \mathrm{~nm}$ and the comparably low diffusion coefficient of only about $1 \cdot 10^{-10} \mathrm{~m}^{2} \mathrm{~s}^{-1}$ as also discussed below.

A structurally more simple hydrocarbon with a conjugated double bond in 1,3-position is 1,3-cyclohexadiene 10a. It undergoes also [4+2]-cycloaddition under formation of the corresponding endoperoxide $\mathbf{1 0 b}$, which reacts further to compound $10 \mathrm{c}$ by cleavage of the peroxide (Scheme $4 \mathrm{c}$ ) $[52,53]$. The degradation of 1,3-cyclohexadiene sets in right after irradiation (Figure S11). However, the measured conversion was only $40 \%$ after $360 \mathrm{~min}$, which is the lowest of all studied 1,3-cyclodienes (Fig. 4). This can be expected hydroperoxide $9 \mathbf{c}$ as side product. $\mathbf{c}$ Addition of ${ }^{1} \mathrm{O}_{2}$ to 1,3-cyclohexadiene 10a leading to the endoperoxide $10 \mathrm{~b}$ followed by conversion to 4-hydroxycyclohex-2-en-1-one 10c by cleavage of the peroxide

based on the comparably low electron density in the absence of donating substituents at the 1,3-positions, reflected by the reaction constant of only $0.07 \cdot 10^{8} \mathrm{Lmol}^{-1} \mathrm{~cm}^{-1}$ (Table 1). Noteworthy, in this case, the increase of conversion due to immobilization of the ZnPc still was a factor of 2 as also observed in the case of $\alpha$-terpinene.

\subsection{Influence of the solvents: $\mathrm{O}_{2}$ lifetime vs diffusion}

A discussion of the observed conversions and activities, respectively, must involve the lifetime and diffusion length of the excited singlet oxygen as well as the diffusion of the substrates. Mass transport becomes increasingly important when dealing with heterogeneous catalysts $[54,55]$. The intrinsic lifetime of ${ }^{1} \mathrm{O}_{2}$ in the absence of a chemical reaction is limited by its deactivation to the triple state by energy transfer to solvent vibrations (physical quenching) $[36,56]$. Typical values reported are $14 \mu$ s for DMF [26], 30-60 $\mu$ s for ACN [2, 23, 24], and only 0.2-4 $\mu$ s for water [25]. Based on a diffusion constant for $\mathrm{O}_{2}$ in water of $2 \cdot 10^{-9} \mathrm{~m}^{2} / \mathrm{s}$ (it scales inversely proportional with the viscosity of the solvent) [57] the average diffusion length of ${ }^{1} \mathrm{O}_{2}$ during its lifetime can be estimated to vary from $20 \mathrm{~nm}$ in water up to $150 \mathrm{~nm}$ in DMF and $513 \mathrm{~nm}$ in ACN. Considering a pore diameter of the npAu of $25 \mathrm{~nm}$ this means that the reaction is restricted to the pore volume of the npAu in case of water and extends only shortly into the solution in case of ACN and DMF. This is an important aspect when further developing this concept of a heterogeneous catalyst. While the nanoporous structure provides a high surface to volume ratio and a large fraction of surface 
per area it is limited by the diffusion of singlet oxygen into the reaction medium. Structuring the $n p A u$ in terms of micrometer sized particles did not only improve the fraction of illuminated sensitizer [22] but also increases the macroscopic surface area of the material. Nevertheless, the measured conversion using the $\mathrm{ZnPc} 1$ immobilized onto the npAu was at least as high as the conversion using the same amount in solution. This effect was lowest for ERGO 9a (factor of 1) and highest for DPBF 3a (factor of 5). Besides the reaction constant of this reaction (Table 1) the diffusion of the substrate towards the npAu surface has to be considered. Here, the diffusion coefficient is dependent on the molecular size and van-der-Waals radius, respectively. It can vary by orders of magnitude from $1.4 \cdot 10^{-9}$ $\mathrm{m}^{2} \mathrm{~s}^{-1}$ for a molecule such as cyclohexene [58], down to a value of about $1 \cdot 10^{-10} \mathrm{~m}^{2} \mathrm{~s}^{-1}$ calculated for ergosterol 9a in water based on the Stokes-Einstein equation. In the latter case the conversion is, thus, hampered by the slow diffusion of the molecule towards the macroscopic surface of the npAu.

\subsection{Stability of the hybrid photocatalyst}

A main motivation to use immobilized sensitizer on heterogeneous npAu is its reuse and recyclability. Simply the reaction medium can be refreshed after use as the sensitizer is not dissolved in the reaction medium. This, however, recommends a good stability of the sensitizer under reaction conditions. We investigated the stability of the hybrid photocatalyst for the oxidation of DPBF in DMF. Four times $5 \mu \mathrm{mol}$ of DPBF was added after the conversion of $100 \%$ was achieved. After the fifth run $85 \%$ of the activity is still present (Fig. 5).

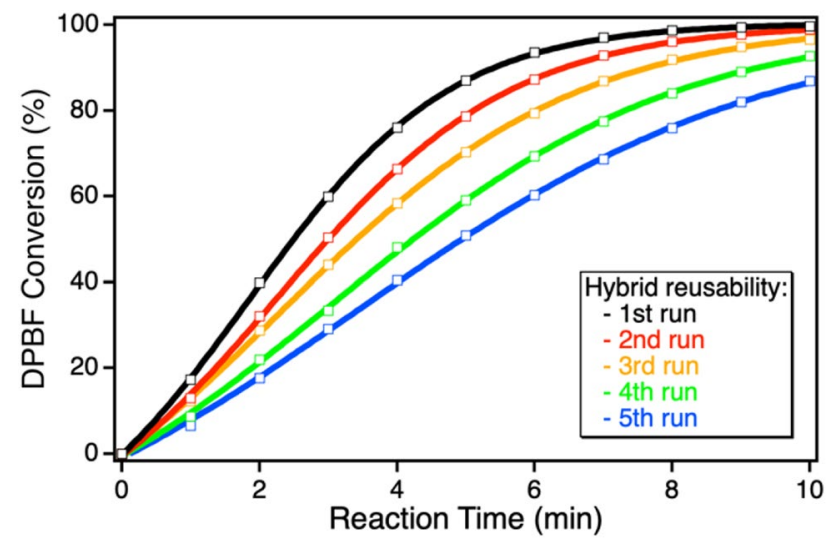

Fig. 5 Repeated photocatalytic conversion of DPBF 3a over time in DMF by oxidation with ${ }^{1} \mathrm{O}_{2}$ employing the $\mathrm{ZnPc}$ photocatalyst immobilized on $\mathrm{npAu}$
The slight decrease in activity is due to the photocatalytic degradation of the bound $\mathrm{ZnPc}$ by ${ }^{1} \mathrm{O}_{2}[59,60]$. This effect is much more pronounced in solution, when DPBF is added a second time to the solution of $0.5 \mathrm{nmol} \mathrm{ZnPc}$, almost no photocatalytic activity was observed.

\section{Conclusion}

Hybrid systems of $\mathrm{ZnPc}$ immobilized on npAu are highly active for the generation of singlet oxygen which can be used for photocatalytic oxidation reactions. Exciting this hybrid system by irradiation with visible light, photooxidations with singlet oxygen are more efficient compared to the $\mathrm{ZnPc}$ dissolved in an organic solvent. The reason is that under irradiation energy transfer from localized plasmon resonance (LSPR) to the immobilized photosensitizer $\mathrm{ZnPc}$ contributes significantly to the formation of singlet oxygen $[16,21,22]$. We demonstrated now the scope of such an approach for [4+2] cycloadditions of eight different substrates of three different classes of 1,3-dienes. The conversions could be widely anticipated based on the reported values for the rate constant of the reaction with ${ }^{1} \mathrm{O}_{2}$. As this system is heterogeneous, it is not limited by the solubility of the sensitizer. The solubility of phthalocyanines in various solvents, especially in water, is an ongoing synthetic quest [61]. Besides functionalization with strongly hydrophilic substituents, immobilization is a viable strategy as we demonstrate. Solubility of the substrate and the singlet oxygen lifetime are limiting factors for the choice of solvent, though. Physical quenching of the singlet state by energy transfer to the solvent molecule reduces the lifetime of ${ }^{1} \mathrm{O}_{2}$ from 30 to $60 \mu$ s for acetonitrile to under $1 \mu \mathrm{s}$ in water. This is particularly important for this heterogeneous system as the ${ }^{1} \mathrm{O}_{2}$ has to diffuse from the pores of the npAu into the solution. The conversion of ABDA 7a which is soluble in water was only $1 \%$ after 60 min as compared to $18 \%$ in DMF under otherwise same conditions. The other benefit of immobilizing the $\mathrm{ZnPc}$ onto npAu is the enhancement of its activity. While this effect was independent of the solvent, we found differences for the various substrates. The largest molecule in this study ERGO 9a did not show any increase in that matter which can be explained by a hampered diffusion from solution to the pores of the hybrid system. Overall, this approach of a synergistic photocatalytic system is versatile in terms of substrates and solvents. The challenge, however, is the limited mass transport and further design of the catalyst. Compared to a dissolved photocatalyst the advantage of the heterogeneous system npAu- $\mathrm{ZnPc}$ is that it can be filtered and used again or cleaned and then functionalized again with $\mathrm{ZnPc}$. 


\section{Experimental section}

\subsection{Materials}

6-Azidohexyl-1-thioacetate (2) [62-64] and 2,9,16,23-tetrakis(2-propyn-1-yloxy)phthalocyanine zinc(II) (1) were prepared as described elsewhere [65]. The co-catalyst tris(benzyl-triazolylmethyl)amine (TBTA) was obtained by literature procedures [66, 67]. Hydroquinone was obtained from Merck and $\mathrm{Cu}(\mathrm{MeCN})_{4} \mathrm{PF}_{6}$ (97\%) from Aldrich. Ethanol (abs., reagent grade), THF (reagent grade, $>99.0 \%$ ), DMF (analytical reagent grade, $99.5 \%$ ), ACN (analytical reagent grade, $>99.5 \%$ ), and $\mathrm{HNO}_{3}$ (analytical reagent grade, $65 \mathrm{wt} \%$ ) were received from VWR and used as obtained. The following substrates for photooxidations were used: 1,3-diphenylisobenzofuran (DPBF, $>95 \%$, TCI), 2,5-diphenylfuran (DPF, > 98\%, TCI), furfuryl alcohol (FFA, $>98 \%$, TCI), 1,3-cyclohexadiene $(1,3-\mathrm{CHD},>97 \%$, Fluka), $\alpha$-terpinene $(>90 \%$, TCI), ergosterol (ERGO, > 95\%, TCI), 9,10-dimethylanthracene (DMA, >98\%, TCI), and 9,10-anthracenediyl-bis(methylene)dimalonic acid (ABDA, 98\%, Sigma-Aldrich). UV-Vis spectra of the ZnPc 1, npAu and for the measurements of the photocatalytic oxidations were recorded on a UV-1600PC UV-Vis spectrometer from VWR.

\subsection{Preparation of nanoporous gold powders}

The npAu powder was prepared according to a modified published procedure $[27,68]$ by dealloying of $\operatorname{Ag}(70$ at $\%) /$ $\mathrm{Au}(30 \mathrm{at} \%$ ) alloy disks (diameter $5 \mathrm{~mm}$, thickness $200 \mu \mathrm{m}$ ) in concentrated $\mathrm{HNO}_{3}(50 \mathrm{~mL}, 65 \mathrm{wt} \%)$ for $24 \mathrm{~h}$. The temperature was constantly held during the dealloying process at $5{ }^{\circ} \mathrm{C}$ using a cryostat. This ensured small pores and ligaments of about $21.7 \pm 3.7 \mathrm{~nm}$ as determined from SEM. To stop the etching process, the samples were repeatedly washed with deionized $\mathrm{H}_{2} \mathrm{O}$ and dried [16, 22, 69]. After dealloying the $\mathrm{npAu}$ disks were cautiously powdered by fragmentation with a metal tweezer.

\subsection{Preparation of the npAu-ZnPc hybrid system}

At first, SAMs were prepared by covering the npAu powder with an ethanolic solution $(5 \mathrm{~mL})$ of 6-azidohexyl-1-thioacetate $(2,1 \mathrm{mmol})$ for $72 \mathrm{~h}[22,68]$. After thoroughly washing with $\mathrm{EtOH}$, in the second step the npAu powder with azide groups were reacted with a solution of the $\mathrm{ZnPc}$ derivative $1(0.15 \mu \mathrm{mol}), \mathrm{Cu}(\mathrm{MeCN})_{4} \mathrm{PF}_{6}(931.8 \mu \mathrm{g}, 2.5 \mu \mathrm{mmol})$, TBTA $(1.326 \mathrm{mg}, 2.5 \mu \mathrm{mol})$, and hydroquinone $(272.5 \mu \mathrm{g}$, $2.5 \mu \mathrm{mmol})$, dissolved in a $\mathrm{THF} / \mathrm{H}_{2} \mathrm{O}$ mixture $(5 \mathrm{~mL}, 3: 1$ v\%) for another $72 \mathrm{~h}$. Finally, any physisorbed material was removed from the hybrid catalyst by washing several times with THF.

\subsection{Characterization methods}

By inductively coupled-plasma mass spectrometry (ICPMS, iCAP Q, Thermo Fisher Scientific GmbH) the quantity of immobilized $\mathrm{ZnPc}$ on npAu hybrid material was determined after dissolving $10 \mathrm{mg}$ of them in ultrapure aqua regia $(2 \mathrm{~mL})$. Morphology of the samples including pore and ligament sizes of the npAu material and zinc distribution in the $\mathrm{npAu}-\mathrm{ZnPc}$ hybrids were determined as described before by SEM and EDX [16, 22]. For XPS characterization, after mounting the samples were directly transferred to the XPS chamber of an ESCALAB250Xi instrument (Thermo Fisher Scientific, East Grinstead, UK) at the University of Oldenburg. The base pressure of the XPS chamber was $1 \cdot 10^{-9}-2 \cdot 10^{-9} \mathrm{mbar}$. The spectra were fitted using the freely available version of XPSCasa.

\subsection{Photocatalytic oxidations}

Photocatalytic oxidations were carried out in a previously described self-built reaction setup consisting of a cylindrical $120 \mathrm{~mL}$ stainless steel tube with quartz windows and a water filter (Figure S3) [22]. For irradiation a $300 \mathrm{~W}$ Xe-arc lamp (LOT qd GmbH, Darmstadt, Germany) with a light intensity of $180 \mathrm{mWcm}^{-2}$ was used. The irradiation source was equipped with a $550 \mathrm{~nm}$ cut-on filter from Andover for simultaneous irradiation of npAu and the immobilized $\mathrm{ZnPc}$ 1. At first, the reaction vessel was filled with $100 \mathrm{~mL}$ of a solvent (DMF, ACN or $\mathrm{H}_{2} \mathrm{O}$ ) and then the powdered hybrid catalyst $(28 \mathrm{mg})$ was added. Weak stirring with a magnetic stirrer was carried out throughout each experiment. The reaction vessel was flushed with $\mathrm{O}_{2}$ at $25{ }^{\circ} \mathrm{C}$ for $10 \mathrm{~min}$ to achieve gas saturation of the solvent. Finally, 3, 5 or $10 \mu \mathrm{mol}$ of a substrate dissolved in $500 \mu \mathrm{L}$ of a solvent (DMF, ACN or $\mathrm{H}_{2} \mathrm{O}$ ) was added. The vessel was closed with a septum and irradiation started. At defined time intervals, aliquots for UV-Vis spectroscopy were taken out of the reactor via a syringe. The photocatalytic activity for every substrate was determined by the conversion over time and quantified by the respective turnover numbers (TON, [converted substrate] (mol)/[irradiated $\mathrm{ZnPc}](\mathrm{mol})$ ) and turnover frequencies (TOF, slope of the plot of TON versus reaction time $\left.\left(\min ^{-1}\right)\right)[22]$.

Supplementary Information The online version contains supplementary material available at https://doi.org/10.1007/s43630-021-00037-7.

Acknowledgements We gratefully acknowledge the work of Petra Witte (Department of Historic Geology and Paleontology, University Bremen) for providing access to the electron microscope and for 
experimental support during the measurements. We also thank Dr. Andre Wichmann and Cornelia Rybarsch-Steinke (Institute of Applied and Physical Chemistry, University Bremen) for sample preparation and measurements of the hybrid catalyst by ICP-MS. We acknowledge Prof. Gunther Wittstock and Mareike Hänsch (University Oldenburg) for XPS characterization of the samples.

Funding Open Access funding enabled and organized by Projekt DEAL. This study was supported by Deutsche Forschungsgemeinschaft (DFG) within research grants WI 4497/3-1 and WO 237/42-1.

\section{Declarations}

Conflict of interest The authors declare that they have no conflicts of interests.

Open Access This article is licensed under a Creative Commons Attribution 4.0 International License, which permits use, sharing, adaptation, distribution and reproduction in any medium or format, as long as you give appropriate credit to the original author(s) and the source, provide a link to the Creative Commons licence, and indicate if changes were made. The images or other third party material in this article are included in the article's Creative Commons licence, unless indicated otherwise in a credit line to the material. If material is not included in the article's Creative Commons licence and your intended use is not permitted by statutory regulation or exceeds the permitted use, you will need to obtain permission directly from the copyright holder. To view a copy of this licence, visit http://creativecommons.org/licenses/by/4.0/.

\section{References}

1. Ohloff, G. (1975). Singlet oxygen: a reagent in organic synthesis. In A. Bruylants, L. Ghosez, \& H. G. Viehe (Eds.), Organic synthesis. (pp. 481-502). Butterworth-Heinemann.

2. Foote, C. S., \& Clennan, E. L. (1995). Properties and reactions of singlet dioxygen. In C. S. Foote, J. S. Valentine, A. Greenberg, \& J. F. Liebman (Eds.), Active oxygen in chemistry. (pp. 105-140). Springer.

3. Ghogare, A. A., \& Greer, A. (2016). Using singlet oxygen to synthesize natural products and drugs. Chemical Reviews, 116(17), 9994-10034. https://doi.org/10.1021/acs.chemrev.5b00726.

4. You, Y. (2018). Chemical tools for the generation and detection of singlet oxygen. Organic \& Biomolecular Chemistry, 16(22), 4044-4060. https://doi.org/10.1039/C8OB00504D.

5. Krasnovsky, A. A., Roumbal, Y. V., \& Strizhakov, A. A. (2008). Rates of ${ }^{1} \mathrm{O}_{2}(1 \Delta \mathrm{g})$ production upon direct excitation of molecular oxygen by $1270 \mathrm{~nm}$ laser radiation in air-saturated alcohols and micellar aqueous dispersions. Chemical Physics Letters, 458(1), 195-199. https://doi.org/10.1016/j.cplett.2008.04.091.

6. Entradas, T., Waldron, S., \& Volk, M. (2020). The detection sensitivity of commonly used singlet oxygen probes in aqueous environments. Journal of Photochemistry and Photobiology, B, 204, 111787. https://doi.org/10.1016/j.jphotobiol.2020.111787.

7. Griesbeck, A. G., Kleczka, M., de Kiff, A., Vollmer, M., Eske, A., \& Sillner, S. (2015). Singlet oxygen and natural substrates: functional polyunsaturated models for the photooxidative degradation of carotenoids. Pure and Applied Chemistry, 87(7), 639-647. https://doi.org/10.1515/pac-2015-0209.

8. DeRosa, M. C., \& Crutchley, R. J. (2002). Photosensitized singlet oxygen and its applications. Coordination Chemistry Reviews, 233-234, 351-371. https://doi.org/10.1016/S0010-8545(02) 00034-6.
9. Wöhrle, D., Suvorova, O., Gerdes, R., Bartels, O., Lapok, L., Baziakina, N., Makarov, S., \& Slodek, A. (2004). Efficient oxidations and photooxidations with molecular oxygen using metal phthalocyanines as catalysts and photocatalysts. Journal of Porphyrins and Phthalocyanines, 8(8), 1020-1041. https://doi.org/ $10.1142 / \mathrm{S} 1088424604000398$.

10. Shinohara, H., Tsaryova, O., Schnurpfeil, G., \& Wöhrle, D. (2006). Differently substituted phthalocyanines: Comparison of calculated energy levels, singlet oxygen quantum yields, photooxidative stabilities, photocatalytic and catalytic activities. Journal of Photochemistry and Photobiology, A, 184(1-2), 50-57. https://doi.org/10.1016/j.jphotochem.2006.03.024.

11. Fernández, L., Esteves, V. I., Cunha, Â., Schneider, R. J., \& Tomé, J. P. C. (2016). Photodegradation of organic pollutants in water by immobilized porphyrins and phthalocyanines. Journal of Porphyrins and Phthalocyanines, 20(01-04), 150-166. https://doi. org/10.1142/S108842461630007X.

12. Temizel, S., Çanak, T. Ç., \& Sevim, A. M. (2020). Novel polymers with cobalt(II)phthalocyanine moieties as effective heterogeneous photocatalysts for visible-light-driven photodegradation of organic dyes in aqueous solutions. Journal of Photochemistry and Photobiology, A, 401, 112741. https://doi.org/10.1016/j.jphotochem. 2020.112741

13. Navaei, Z., \& Zanjanchi, M. A. (2020). Synthesis of an efficient photocatalyst by incorporation of phthalocyanine into KIT6. SN Applied Sciences, 2(6), 1037. https://doi.org/10.1007/ s42452-020-2845-6.

14. Wittstock, A., \& Bäumer, M. (2014). Catalysis by unsupported skeletal gold catalysts. Accounts of Chemical Research, 47(3), 731-739. https://doi.org/10.1021/ar400202p.

15. Wittstock, A., Biener, J., Erlebacher, J., \& Bäumer, M. (2012). Nanoporous Gold: from an Ancient Technology to a Novel Material (1ed., Vol. 1, RSC Nanoscience and Nanotechnology, Vol. 1): RSC

16. Steinebrunner, D., Schnurpfeil, G., Wöhrle, D., \& Wittstock, A. (2020). Photocatalytic coatings based on a zinc(II) phthalocyanine derivative immobilized on nanoporous gold leafs with various pore sizes. RSC Advances, 10(1), 53-59. https://doi.org/10.1039/ C9RA08841E.

17. Kotiaho, A., Lahtinen, R., \& Lemmetyinen, H. (2011). Photoinduced processes in chromophore-gold nanoparticle assemblies. Pure and Applied Chemistry, 83(4), 813-821. https://doi.org/10. 1351/PAC-CON-10-08-19.

18. Kotiaho, A., Lahtinen, R., Efimov, A., Metsberg, H.-K., Sariola, E., Lehtivuori, H., Tkachenko, N. V., \& Lemmetyinen, H. (2010). Photoinduced charge and energy transfer in phthalocyanine-functionalized gold nanoparticles. Journal of Physical Chemistry C, 114(1), 162-168. https://doi.org/10.1021/jp9087173.

19. Christopher, P., Xin, H. L., \& Linic, S. (2011). Visible-lightenhanced catalytic oxidation reactions on plasmonic silver nanostructures. Nature Chemistry, 3(6), 467-472. https://doi.org/10. 1038/nchem. 1032.

20. Detsi, E., Salverda, M., Onck, P. R., \& De Hosson, J. T. M. (2014). On the localized surface plasmon resonance modes in nanoporous gold films. Journal of Applied Physics, 115(4), 044308. https:// doi.org/10.1063/1.4862440.

21. Steinebrunner, D., Schnurpfeil, G., Kohröde, M., Epp, A., Klangnog, K., Tapia Burgos, J. A., Wichmann, A., Wöhrle, D., \& Wittstock, A. (2020). Impact of photosensitizer orientation on the distance dependent photocatalytic activity in zinc phthalocyanine-nanoporous gold hybrid systems. RSC Advances, 10(39), 23203-23211. https://doi.org/10.1039/D0RA03891A.

22. Steinebrunner, D., Schnurpfeil, G., Wichmann, A., Wöhrle, D., \& Wittstock, A. (2019). Synergistic effect in zinc phthalocyaninenanoporous gold hybrid materials for enhanced photocatalytic 
oxidations. Catalysts, 9(6), 555. https://doi.org/10.3390/catal 9060555

23. Ogilby, P. R., \& Foote, C. S. (1983). Chemistry of singlet oxygen. 42. Effect of solvent, solvent isotopic substitution, and temperature on the lifetime of singlet molecular oxygen (1.DELTA.g). Journal of the American Chemical Society, 105(11), 3423-3430. https://doi.org/10.1021/ja00349a007.

24. Hurst, J. R., McDonald, J. D., \& Schuster, G. B. (1982). Lifetime of singlet oxygen in solution directly determined by laser spectroscopy. Journal of the American Chemical Society, 104(7), 2065-2067. https://doi.org/10.1021/ja00371a065.

25. Salokhiddinov, K. I., Byteva, I. M., \& Gurinovich, G. P. (1981). Lifetime of singlet oxygen in various solvents. Journal of Applied Spectroscopy, 34(5), 561-564. https://doi.org/10.1007/BF006 13067.

26. Adams, D. R., \& Wilkinson, F. (1972). Lifetime of singlet oxygen in liquid solution. Journal of the Chemical Society, Faraday Transactions, 2(68), 586-593. https://doi.org/10.1039/F2972 6800586.

27. Qian, L. H., \& Chen, M. W. (2007). Ultrafine nanoporous gold by low-temperature dealloying and kinetics of nanopore formation. Applied Physics Letters, 91(8), 083105. https://doi.org/10.1063/1. 2773757.

28. Love, J. C., Estroff, L. A., Kriebel, J. K., Nuzzo, R. G., \& Whitesides, G. M. (2005). Self-assembled monolayers of thiolates on metals as a form of nanotechnology. Chemical Reviews, 105(4), 1103-1170. https://doi.org/10.1021/cr0300789.

29. Heinrich, T., Traulsen, C. H. H., Darlatt, E., Richter, S., Poppenberg, J., Traulsen, N. L., Linder, I., Lippitz, A., Dietrich, P. M., Dib, B., Unger, W. E. S., \& Schalley, C. A. (2014). The versatility of "click" reactions: molecular recognition at interfaces. $R S C$ Advances, 4(34), 17694-17702. https://doi.org/10.1039/C4RA0 1730G.

30. Merkel, P. B., \& Kearns, D. R. (1975). Rate constant for the reaction between 1,3-diphenylisobenzofuran and singlet oxygen. Journal of the American Chemical Society, 97(2), 462-463. https://doi. org/10.1021/ja00835a063.

31. Clennan, E. L., \& Mehrsheikhmohammadi, M. E. (1984). Mechanism of endoperoxide formation. 2. Possibility of exciplexes on the reaction coordinates. Journal of Organic Chemistry, 49(7), 1321-1322. https://doi.org/10.1021/jo00181a051.

32. Haag, W. R., Hoigne, J., Gassman, E., \& Braun, A. M. (1984). Singlet oxygen in surface waters-Part I: Furfuryl alcohol as a trapping agent. Chemosphere, 13(5-6), 631-640. https://doi.org/ 10.1016/0045-6535(84)90199-1.

33. Albiter, E., Alfaro, S., \& Valenzuela, M. A. (2015). Photosensitized oxidation of 9,10-dimethylanthracene with singlet oxygen by using a safranin $\mathrm{O} /$ silica composite under visible light. Photochemical \& Photobiological Sciences, 14(3), 597-602. https:// doi.org/10.1039/C4PP00261J.

34. Kuznetsova, N. A., Gretsova, N. S., Yuzhakova, O. A., Negrimovskii, V. M., Kaliya, O. L., \& Luk'yanets, E. A. (2001). New reagents for determination of the quantum efficiency of singlet oxygen generation in aqueous media. Russian Journal of General Chemistry, 71(1), 36-41. https://doi.org/10.1023/A:1012369120 376.

35. Monroe, B. M. (1981). Rate constants for the reaction of singlet oxygen with conjugated dienes. Journal of the American Chemical Society, 103(24), 7253-7256. https://doi.org/10.1021/ja004 $14 \mathrm{a} 035$.

36. Wilkinson, F., Helman, W. P., \& Ross, A. B. (1995). Rate constants for the decay and reactions of the lowest electronically excited singlet state of molecular oxygen in solution. An expanded and revised compilation. Journal of Physical and Chemical Reference Data, 24(2), 663-677. https://doi.org/10.1063/1.555965.
37. Matheson, I. B. C., Lee, J., Yamanashi, B. S., \& Wolbarsht, M. L. (1974). Measurement of the absolute rate constants for singlet molecular oxygen (1.DELTA.g) reaction with 1,3-diphenylisobenzofuran and physical quenching by ground state molecular oxygen. Journal of the American Chemical Society, 96(11), 33433348. https://doi.org/10.1021/ja00818a001.

38. Spiller, W., Kliesch, H., Wöhrle, D., Hackbarth, S., Röder, B., \& Schnurpfeil, G. (1998). Singlet oxygen quantum yields of different photosensitizers in polar solvents and micellar solutions. Journal of Porphyrins and Phthalocyanines, 2(2), 145-158. https:// doi.org/10.1002/(SICI)1099-1409(199803/04)2:2\%3c145::AIDJPP60\%3e3.0.CO;2-2.

39. Braun, A. M., Dahn, H., Gassmann, E., Gerothanassis, I., Jakob, L., Kateva, J., Martinez, C. G., \& Oliveros, E. (1999). $(2+4)$-Cycloaddition with singlet oxygen. 170-lnvestigation of the reactivity of furfuryl alcohol endoperoxide. Photochemistry and Photobiology, 70(6), 868-874. https://doi.org/10.1111/j.17511097.1999.tb08295.x.

40. Montagnon, T., Kalaitzakis, D., Triantafyllakis, M., Stratakis, M., \& Vassilikogiannakis, G. (2014). Furans and singlet oxygen-why there is more to come from this powerful partnership. Chemical Communications, 50(98), 15480-15498. https://doi.org/10.1039/ C4CC02083A.

41. Steinebrunner, D., Schnurpfeil, G., Thayssen, J., Tapia Burgos, J. A., Wichmann, A., Wöhrle, D., \& Wittstock, A. (2021). Comparison of the photocatalytic activity of novel hybrid photocatalysts based on phthalocyanines, subphthalocyanines and porphyrins immobilized onto nanoporous gold. RSC Advances, 11(19), 11364-11372. https://doi.org/10.1039/D1RA01331A.

42. Schmidt, R., Schaffner, K., Trost, W., \& Brauer, H. D. (1984). Wavelength-dependent and dual photochemistry of the endoperoxides of anthracene and 9,10-dimethylanthracene. Journal of Physical Chemistry, 88(5), 956-958. https://doi.org/10.1021/ j150649a022.

43. Albiter, E., Alfaro, S., \& Valenzuela, M. A. (2012). Photosensitized oxidation of 9,10-dimethylanthracene on dye-doped silica composites. International Journal of Photoenergy, 2012, 987606. https://doi.org/10.1155/2012/987606.

44. Scanone, A. C., Gsponer, N. S., Alvarez, M. G., \& Durantini, E. N. (2017). Photodynamic properties and photoinactivation of microorganisms mediated by 5,10,15,20-tetrakis(4-carboxyphenyl)porphyrin covalently linked to silica-coated magnetite nanoparticles. Journal of Photochemical and Photobiological, A, 346, 452-461. https://doi.org/10.1016/j.jphotochem.2017.06.039.

45. Mora, S. J., Milanesio, M. E., \& Durantini, E. N. (2013). Spectroscopic and photodynamic properties of 5,10,15,20-tetrakis[4-(3- $N$, $\mathrm{N}$-dimethylaminopropoxy)phenyl]porphyrin and its tetracationic derivative in different media. Journal of Photochemical and Photobiological, A, 270, 75-84. https://doi.org/10.1016/j.jphotochem. 2013.07.013.

46. Ronzani, F., Costarramone, N., Blanc, S., Benabbou, A. K., Bechec, M. L., Pigot, T., Oelgemöller, M., \& Lacombe, S. (2013). Visible-light photosensitized oxidation of $\alpha$-terpinene using novel silica-supported sensitizers: Photooxygenation vs. photodehydrogenation. Journal of Catalysis, 303, 164-174. https://doi.org/10. 1016/j.jcat.2013.04.001.

47. Günther, Schenck, O., \& Ziegler, K. (1944). Die Synthese des Ascaridols. Naturwissenschaften, 32(14), 157-157. https://doi. org/10.1007/BF01467891.

48. Schenck, O. (1944). Colloquium am 26. Juni 1944. Angewandte Chemie, 57(13-16), 101-102. https://doi.org/10.1002/ange.19440 571305.

49. Albro, P. W., Corbett, J. T., \& Schroeder, J. L. (1994). Doubly allylic hydroperoxide formed in the reaction between sterol 5,7-dienes and singlet oxygen. Photochemistry and Photobiology, 
60(4), 310-315. https://doi.org/10.1111/j.1751-1097.1994.tb051 09.x.

50. Ponce, M. A., Ramirez, J. A., Galagovsky, L. R., Gros, E. G., \& Erra-Balsells, R. (2002). A new look into the reaction between ergosterol and singlet oxygen in vitro. Photochemical \& Photobiological Sciences, 1(10), 749-756. https://doi.org/10.1039/B2044 $52 \mathrm{H}$.

51. Fisch, M. H., Ernst, R., Flick, B. H., Arditti, J., Barton, D. H. R., Magnus, P. D., \& Menzies, I. D. (1973). Identity of ergosterol '5 $\beta, 8 \beta$-peroxide.' Journal of the Chemical Society, Chemical Communications, 15, 530-530. https://doi.org/10.1039/C3973 0000530.

52. Camussi, I., Mannucci, B., Speltini, A., Profumo, A., Milanese, C., Malavasi, L., \& Quadrelli, P. (2019). g-C3N4-Singlet oxygen made easy for organic synthesis: Scope and limitations. ACS Sustainable Chemistry \& Engineering, 7(9), 8176-8182. https:// doi.org/10.1021/acssuschemeng.8b06164.

53. Kaneko, C., Sugimoto, A., \& Tanaka, S. (1974). A facile one-step synthesis of cis-2-cyclopentene- and cis-2-cyclohexene-1,4-diols from the corresponding cyclodienes. Synthesis, 1974(12), 876877. https://doi.org/10.1055/s-1974-23462.

54. Johnson, B., Beiler, A. M., McCarthy, B. D., \& Ott, S. (2020). Transport phenomena: challenges and opportunities for molecular catalysis in metal-organic frameworks. Journal of the American Chemical Society, 142(28), 11941-11956. https://doi.org/10.1021/ jacs.0c02899.

55. Sun, L. B., Liu, X. Q., \& Zhou, H. C. (2015). Design and fabrication of mesoporous heterogeneous basic catalysts. Chemical Society Reviews, 44(15), 5092-5147. https://doi.org/10.1039/C5CS0 0090D.

56. Schmidt, R., \& Afshari, E. (1992). Collisional deactivation of $\mathrm{O}_{2}(1 \Delta \mathrm{g})$ by solvent molecules. Comparative experiments with $16 \mathrm{O}_{2}$ and $18 \mathrm{O}_{2}$. Berichte der Bunsengesellschaft für physikalische Chemie, 96(6), 788-794. https://doi.org/10.1002/bbpc.19920 960610.

57. Han, P., \& Bartels, D. M. (1996). Temperature dependence of oxygen diffusion in $\mathrm{H}_{2} \mathrm{O}$ and $\mathrm{D}_{2} \mathrm{O}$. Journal of Physical Chemistry, 100(13), 5597-5602. https://doi.org/10.1021/jp952903y.

58. Holz, M., Heil, S. R., \& Sacco, A. (2000). Temperature-dependent self-diffusion coefficients of water and six selected molecular liquids for calibration in accurate 1H NMR PFG measurements. Physical Chemistry Chemical Physics: PCCP, 2(20), 4740-4742. https://doi.org/10.1039/B005319H.

59. Sobbi, A. K., Wöhrle, D., \& Schlettwein, D. (1993). Photochemical stability of various porphyrins in solution and as thin film electrodes. Journal of the Chemical Society, Perkin Transactions, 2(3), 481-488. https://doi.org/10.1039/P29930000481.
60. Schnurpfeil, G., Sobbi, A. K., Spiller, W., Kliesch, H., \& Wöhrle, D. (1997). Photo-oxidative stability and its correlation with semiempirical MO calculations of various tetraazaporphyrin derivatives in solution. Journal of Porphyrins and Phthalocyanines, 1(2), 159-167. https://doi.org/10.1002/(SICI)1099-1409(199704) 1:2\%3c159::AID-JPP19\%3e3.0.CO;2-8.

61. Dumoulin, F., Durmuş, M., Ahsen, V., \& Nyokong, T. (2010). Synthetic pathways to water-soluble phthalocyanines and close analogs. Coordination Chemistry Reviews, 254(23-24), 27922847. https://doi.org/10.1016/j.ccr.2010.05.002.

62. Sodji, Q. H., Patil, V., Kornacki, J. R., Mrksich, M., \& Oyelere, A. K. (2013). Synthesis and structure-activity relationship of 3-hydroxypyridine-2-thione-based histone deacetylase inhibitors. Journal of Medicinal Chemistry, 56(24), 9969-9981. https://doi. org/10.1021/jm401225q.

63. Ligeour, C., Meyer, A., Vasseur, J.-J., \& Morvan, F. (2012). Bisand tris-alkyne phosphoramidites for multiple 5'-labeling of oligonucleotides by click chemistry. European Journal of Organic Chemistry, 2012(9), 1851-1856. https://doi.org/10.1002/ejoc. 201101763.

64. Wu, X., Ling, C.-C., \& Bundle, D. R. (2004). A new homobifunctional p-nitro phenyl ester coupling reagent for the preparation of neoglycoproteins. Organic Letters, 6(24), 4407-4410. https://doi. org/10.1021/ol048614m.

65. Wöhrle, D., Tsaryova, O., Semioshkin, A., Gabel, D., \& Suvorova, O. (2013). Synthesis and photochemical properties of phthalocyanine zinc(II) complexes containing o-carborane units. Journal of Organometallic Chemistry, 747, 98-105. https://doi.org/ 10.1016/j.jorganchem.2013.03.020.

66. Chan, T. R., Hilgraf, R., Sharpless, K. B., \& Fokin, V. V. (2004). Polytriazoles as copper(I)-stabilizing ligands in catalysis. Organic Letters, 6(17), 2853-2855. https://doi.org/10.1021/ol0493094.

67. Brassard, C. J., Zhang, X., Brewer, C. R., Liu, P., Clark, R. J., \& Zhu, L. (2016). Cu(II)-catalyzed oxidative formation of 5,5'-bistriazoles. Journal of Organic Chemistry, 81(24), 12091-12105. https://doi.org/10.1021/acs.joc.6b01907.

68. Wichmann, A., Schnurpfeil, G., Backenköhler, J., Kolke, L., Azov, V. A., Wöhrle, D., Bäumer, M., \& Wittstock, A. (2014). A versatile synthetic strategy for nanoporous gold-organic hybrid materials for electrochemistry and photocatalysis. Tetrahedron, 70(36), 6127-6133. https://doi.org/10.1016/j.tet.2014.03.091.

69. Wittstock, A., Wichmann, A., \& Bäumer, M. (2012). Nanoporous gold as a platform for a building block catalyst. ACS Catalysis, 2(10), 2199-2215. https://doi.org/10.1021/cs300231u.

\section{Authors and Affiliations}

\section{David Steinebrunner ${ }^{1,2}$ (D) Günter Schnurpfeil ${ }^{3} \cdot$ Hans Hannes Doebler ${ }^{1} \cdot$ Jorge Adrian Tapia Burgos $^{1,2}$.D $^{-}$ Dieter Wöhrle ${ }^{3} \cdot$ Arne Wittstock $^{1,2}$ (])}

1 Institute of Applied and Physical Chemistry and Center for Environmental Research and Sustainable Technology, University Bremen, Leobener Str. 6, 28359 Bremen, Germany

2 MAPEX Center for Materials and Processes, University Bremen, Bibliothekstr. 1, 28359 Bremen, Germany
3 Organic and Macromolecular Chemistry, University Bremen, Leobener Str. NW2, 28359 Bremen, Germany 